\title{
Prediction of Water Contamination Detection using Thermal Image Processing
}

\author{
R.Venkatesan ${ }^{1}$, T. Jemima Jebaseeli ${ }^{2}$, K. Ramalakshmi ${ }^{3}$ \\ ${ }^{1}$ Assistant Professor, Department of Computer Science and Engineering, Karunya Institute of Technology and Sciences, \\ Coimbatore, Tamilnadu, India. rlvenkei_2000@karunya.edu \\ ${ }^{2}$ Assistant Professor, Department of Computer Science and Engineering, Karunya Institute of Technology and Sciences, \\ Coimbatore, Tamilnadu, India. jemima_jeba@karunya.edu \\ ${ }^{3}$ Assistant Professor, Department of Computer Science and Engineering, Karunya Institute of Technology and Sciences, \\ Coimbatore, Tamilnadu, India. ramalakshmi@karunya.edu
}

\begin{abstract}
The increased rate of water-borne diseases is quite alarming and it is caused due to the poor quality of water. The toxins directly or indirectly find their way into water posing serious threats to the entire ecosystem. The work presented uses the technique in thermal image processing to monitor and detect the contamination in water. This method pertains to altering and analyzing the pictorial information of water with data sets representing various contaminants. The objective here is to visually monitor and statically evaluate some aspect of the images of water that is not readily apparent in its original form and enhance the image quality. The clean water templates and the infrared templates are compared using the GUI created in the MatLab platform. The non-contaminated areas and the contaminated areas are differentiated using color thresholding and effective matching is done with high accuracy using a pure water template.
\end{abstract}

Key words: Clustering, thermal image, water contamination, water quality.

\section{INTRODUCTION}

The World Health Organization has reported that over 80 percent of health-related diseases bedeviling the developing nations are related to poor water quality, which results in 30 percent mortality [1]. The population raise and industrial growth have resulted in elevating water pollution levels. Water quality in general terms refers to several basic attributes like physical, biological, and chemical features of water. Apart from industrial and domestic sources, water gets contaminated in so many ways [2]. Sometimes the bottled water has contaminants and microplastic particles that are unsafe. The toxins directly or indirectly find their way into water posing serious threats to the entire ecosystem. Water sanitation issues are faced in both rural and urban areas but most often in rural places.
To address this issue and outweigh the conventional laboratorybased monitoring methods and sensor-based detection methods, the proposed system uses thermal imaging to identify the contaminants in water with more accuracy thereby taking actions to improve the water quality [3]. The thermal image processing techniques pave an easy way to give accurate results for monitoring the contaminated water. The uniqueness of the proposed system is that it does water quality monitoring with low cost, low powered, high frequency, and high mobility. Thermal imaging or thermal image processing is the process of converting infrared radiation into visible images that depict the spatial distribution of temperature differences in a scene viewed by a thermal camera. Thermal imaging of water contamination detection systemaims to safeguard the people of urban and rural areas from water-borne diseases [4]. Monitoring serves a range of purposes, from the control of chemical and ecological status. Major improvements are benefited from thermal imaging of water as the monitoring approaches tend to detect contaminants accurately. This work results in detecting the water quality by the variation in clean water images and thermal images of contaminated water.

\section{LITERATURE REVIEW}

Monitoring the water quality is of great importance as it helps to determine the human health of livelihoods dependent on clean reliable water supplies at a snapshot of time. This monitoring is crucial for ensuring the sustained health of water bodies. This paper is concentrate on the damages present in the water and rectifies the content to inform the responsible for cleaning nature in periodic time and maintain it in the proper state to saturate the content into the correct rate [5]. So for using a thermal camera, the images are captured and content with the color map is frozen using pseudo gray image processing thereby it is partitioned with the intensity of the data and it identified those contaminated parts as separately with the content which are all bad and which need to clean properly [6-8].The comparative study on existing techniques is shown in Table 1. 


\section{METHODOLOGY}

There are nine important steps in the proposed system.

1. Preprocessing of the data

2. Gray image conversion

3. Colormap reproduction

4. Pseudorandom noise removal

5. The intensity of the image capturing

6. High gradient scaling to be identified

7. Filter operation

8. Clustering the part which the content to be removed

9. Classify the part

\subsection{Preprocessing of the data}

Preprocessing is the underlying step for the transformation of a thermal picture into a grayscale picture which is trailed by the segmentation procedure and resizing of the picture to take out undesirable pieces of the polluted water.

\subsubsection{Image filtering}

Wiener and median filters are utilized in this paper for the segmentation of pictures. The median filter gives a great outcome when contrasted with the wiener channel. So the median filter is utilized for the segmentation procedure.

\subsubsection{Median Filter}

To dispense with noise from a picture, the nonlinear median filter is utilized. It is extremely beneficial to eliminate noise and saving edges. The procedure of a median filter is finished by affecting across the pixel image through pixel, trading each an incentive with neighboring median pixels esteem. The structure of neighbors is known as a window that floats pixel by pixel in the overall image. The median filtering calculation delineates in the window to organize the pixel esteems in expanding or diminishing requests. The center of two normal qualities, the median is determined. Ordinary windows dimensions are $5 \times 5,7 \times 7$, and $3 \times 3$, or the 5 point window is evaluated for averaging.

\subsubsection{Image Enhancement}

Location of an edge in image enhancement is utilized to make a visual presentation to feature or improve the element of a picture, for example, differentiation or limits which is progressively appropriate for examination. Image enhancement incorporates different control and dark level, crispening edge and clamor consumption, improving, pseudo shading, separating, amplification addition, and so forth. For picture upgrade of defiled water, the histogram equalization is utilized.

\subsubsection{Image Segmentation}

Segmentation is be grouped into four sorts in particular characterization based, edge-based, the limit based, and areabased segmentation. The shading based segmentation is utilized to fragment the defiled piece of the water. The premise of shading is accomplished by the segmented picture. By arranging objects dependent on shading in a picture this should be possible. Examination of the picture should be possible straightly on a genuine picture or across the singular shade of plane. The count of the mean estimation requires shading and contrast estimations of each RGB pixel of a picture. For shading based segmentation, the particle swarm improvement calculation is utilized.

\subsection{Gray Image Conversions}

A grayscale picture is characterized in which the estimation of every pixel is a solitary example which is the measure of light that is intensity information. Grayscale pictures are unmistakable with two highly contrasting hues. In the middle, they have numerous shades of dim. To figure the grayscale esteems a typical procedure utilized to go with the standards of photometry or colorimetric. Transformation of shading from a colorspace dependent on a common gamma packed RGB shading model to a grayscale portrayal of its luminance, the gamma should initially be expelled using gamma development to change the picture to a direct RGB colorspace with the goal that the suitable weighted whole is applied to the straight shading parts to compute the direct luminance which would then be able to be gamma compacted back again if the grayscale result is additionally to be encoded and put away in an ordinary nonlinear colorspace. Straight luminance is resolved as a weighted aggregate of the three direct force esteems.

\subsection{Colormap Reproduction}

Shading is added to the created grayscale picture which delivers a colorized picture. By utilizing the accessible shading picture the shading data is recovered close by anatomical area. The calculation duplicates the shade of the grayscale picture utilizing the shading likeness between the subject picture and the grayscale picture. The colormap plots luminance segments to relating shading segments which give the RGB incentive to a pixel with a specific luminance. It is dynamic as they change when another picture is picked. The colormap is expressed as,

$\mathrm{Z}: \mathrm{Y}-->\{\mathrm{R}, \mathrm{G}, \mathrm{B}\}$

Every one of the shading pixels is changed over to luminance utilizing the above condition. The relationship between the shading and the luminance will be high. By utilizing the produced shading map, the contrast between the first grayscale picture and the recovered grayscale picture is determined.

\subsection{Pseudo random noise removal}

In certain image structures, as in fluorescence microscopy or cosmology, only a foreordained number of photons assembled on account of various physical objectives. The ensuing pictures experience the ill effects of sign ward clamor, which is shown as a Poisson scattering, and a low sign to-upheaval extent. Regardless, the greater part of the examination on clamor decline counts revolves around without signal gaussian clamor. Moreover Markov models applied with a framework that 
advantageously portrays the spatial and interscale conditions which are the properties of progress coefficients of ordinary pictures. At the present time, convincing denoising figuring for Poisson-Gaussian noise is proposed using the contour let change, disguised Markov models, and upheaval estimation in the evolving region. By supplement, the figuring by cycle turning and wiener isolating for extra upgrades. Finally preliminary outcomes showed with diversions and fluorescence microscopy pictures that display the improved introduction of the proposed approach.

Computerized pictures are normal in lives as a result of advances in blended media, web, PCs, and the far-reaching of advantageous imaging devices, for instance, buyer propelled cameras and camcorders. Picture acquirement and dealing with are in like manner standard in clinical development and the organization business. Such demands have subsequently incited the movement of picture sensors, for instance, the chargecoupled device (CCD) and the correlative metal oxide semiconductor (CMOS). Owing to the improvement of picture sensor gear, extended spatial objectives have achieved a reduced sensor pixel size, which causes the advancement of the photon impact.

\subsubsection{Evacuate noise by linear filtering}

To utilize direct sifting to expel specific sorts of commotion, certain channels, averaging or Gaussian channels, are proper for this reason. For instance, an averaging channel is valuable for expelling grain commotion from a photo for more data about straight separating utilizing imfilter.

\subsubsection{Expel noise using an averaging filter and a median filter}

This model tells the best way to expel salt and pepper commotion from a picture utilizing an averaging channel and a middle channel to permit correlation of the outcomes. These two sorts of separating both sets the estimation of the yield pixel to the normal of the pixel esteem in the area around the relating input pixel. In any case, with middle sifting, the estimation of a yield pixel is dictated by the middle of the local pixels, instead of the mean. The middle is substantially less touchy than they intend to outrageous qualities (called exceptions). Middle separating is in this manner better ready to expel these exceptions without diminishing the sharpness of the picture.

\subsection{Intensity of the image capturing}

Force alludes to the measure of light or the numerical estimation of a pixel. For instance, in grayscale pictures, it's delineated by the dim level an incentive at every pixel. Compute the entirety of $\mathrm{R}+\mathrm{G}+\mathrm{B}$ for all pixels separated by 3 then by the complete number of pixels.

$\mathrm{S}=0$;

For $(\mathrm{I}=0$ to $\mathrm{n}-1)$

\{

$\mathrm{S}=\mathrm{S}+\mathrm{Ri}+\mathrm{Gi}+\mathrm{Bi}$

\}
Level $=\mathrm{S} /(3 * \mathrm{n})$

This will give a level an incentive between 0 (dull) and 255 (splendid).

\subsubsection{Pixels and intensity}

The camera is used to catch pictures that has a given pixel thickness and dynamic range, and these parameters administer the camera's capacity to precisely record the bright light originating from the example. Figure out how pixel thickness is identified with goals, the significance of the camera's dynamic range, and the distinction between fluorescence foundation and imaging framework clamor. Here, there are 3 major functions are there which are following

- Goals of computerized pictures that relies upon the number of pixels.

- Utilizing the full unique scope of the camera.

- Commotion versus foundation.

\subsubsection{Goals of computerized pictures, for the most part, relies upon the number of pixels}

The computerized picture has to be caught on a fluorescence magnifying lens is a guide of the photons that are produced from the fluorophores present, after brightening. The picture is partitioned into various similarly measured units called pixels. Every pixel in the picture speaks to a discrete territory and has related power esteem, so that in grayscale lower forces show up dull (dark) and higher powers show up exceptionally light (white). The pixels are typically pseudo colored to coordinate the shade of each fluorophore's outflow, and how splendid the shading shows up relies upon the force esteem related with the pixel. Pseudo coloring makes it simpler to see overlays of more fluorescent shading.

The power esteem speaks to the number of photons distinguished by the camera at a particular area, so the advanced picture shows that would check whether glanced through the oculars at lit up test. Regularly the camera will take a superior picture than the eyes to see a bigger unique range. Pixels in a given picture are a no different sizes, yet pictures are isolated into a couple of huge pixels or a great many little pixels. The greatest number of pixels allocated to the picture is reliant on the camera that is used to take the picture. At the point when increment the number of pixels in a picture however keep the picture size the equivalent before obtaining the picture, will build the picture's goals.

\subsubsection{Utilizing the full unique scope of the camera}

The camera is used to recognize the fluorescent sign has a unique range. At the point when secure a picture, photons are gathered by the indicator. With expanding introduction time, an ever increasing number of photons are gathered by the indicator, bringing about more splendid pixels. Be that as it may, the identifier has a breaking point on the number of photons it gathers, and once this cutoff has arrived at the pixel gets immersed. Any photons showing up at the locator after immersion has arrived won't be tallied; soaked pixels hence don't give quantitatively precise information. The dynamic 
range is a marker of what number of photons the finder gathers before getting soaked. A camera with a bigger powerful range has the option to see dimmer signs.

\subsubsection{Commotion versus a foundation}

Both commotion and foundation add to undesirable fluorescence force. The clamor is characterized as the undesirable vague fluorescence that originates from the imaging framework; this incorporates commotion from the excitation source, camera, and outer light source. The term foundation alludes to the undesirable vague fluorescence that originates from the auto fluorescence of tests, vessels, and imaging medium, or from the fluorescent sign that originates from fluorophores not bound to explicit targets.

\subsection{High gradient scaling to be identified}

An image slope is a directional change in the force or shading in an image. The angle of the picture is one of the key structures hinders in picture preparation. For instance, the Canny edge locator utilizes a picture angle for edge identification. $\mathrm{FX}=\operatorname{gradient}(\mathrm{F})$ where $\mathrm{F}$ is a vector restores the one-dimensional numerical inclination of F.FX compares to, the distinctions toward the path. $[\mathrm{FX}, \mathrm{FY}]=\operatorname{gradient}(\mathrm{F})$, where $\mathrm{F}$ is a framework restores the segments of the two-dimensional numerical slope. FX relates to, the distinctions in the section bearing. The inclination is firmly identified with the subordinate; however, it isn't itself a subsidiary the estimation of the angle at a point is a digression vector, while the estimation of the subordinate at a point is a cotangent vector. The numerical inclination of capacity is an approach to gauge the estimations of the halfway subsidiaries in each measurement utilizing the known estimations of the capacity at specific focuses. Picture inclinations are utilized to remove data from pictures. Angle pictures are made from the first picture by and large by convolving with a channel, one of the easiest being the Sobel channel for this reason [10]. Every pixel of a slope picture gauges the adjustment in the power of that equivalent point in the first picture in a provided guidance. The pixels with the biggest slope esteem toward the inclination become edge pixels, and edges might be followed toward the path opposite to the angle bearing. One case of an edge recognition calculation that utilizes inclinations is the Canny edge locator [11]. Picture slopes are utilized for powerful elements and surface coordinating. Distinctive lighting or camera properties makes two pictures of a similar scene have radically unique pixel esteems. This makes the coordinating calculations to neglect the coordinate fundamentally as same as or indistinguishable highlights. One approach to tackle this is to process the surface or highlight the marks that are dependent on angle pictures registered from the first pictures. These angles are less defenseless to lighting and camera changes, so coordinating blunders are diminished.

\subsection{Filter operation, Clustering the part which the content to be removed and Classify the part}

The continuous image with a substantial sequence of HSV data are taken from the thermal image, filter image with Gaussian mixture model once the image is converted into gray scaling, based on the arrived data impulse region through segmented part and every binary sequence is merged with color mapping data and from there features a selection of segmented data is retrieved through GLCM data and ANN classifiers their perfect insubstantial data of an image is removed and warning of other such data are removed. Modules here are common: Take any Gaussian mixture model, Region of interest, and ANN.

\subsection{Gaussian mixture model}

In the realm of machine learning, there are two fundamental regions: supervised and unsupervised learning. The primary contrast between the two lies in the idea of the information just as the methodologies used to manage it. Bunching is an unaided learning issue to discover groups of focuses in the dataset that share some regular attributes.A Gaussian Mixture is a function that is comprised of several Gaussians, each identified by $k \in$ $\{1, \ldots, K\}$, where $K$ is the number of clusters of the dataset. Each Gaussian $k$ in the mixture is comprised of the following parameters:

- A mean $\mu$ that defines its center.

- A covariance $\Sigma$ that defines its width. This would be equivalent to the dimensions of an ellipsoid in a multivariate scenario.

- A mixing probability $\pi$ that defines how big or small the Gaussian functions.

\subsection{Region of interest of intensity classifier}

The portion of the image has to be filtered atthe region of interest (ROI). The toolbox supports a lot of ROI objects that is utilized to make ROIs of numerous shapes such as circles, ovals, polygons, square shapes, and hand-drawn shapes. After creation, the ROI object properties are utilized to tweak their appearance and work. Also, the ROI objects bolster object capacities and occasions that is utilized to actualize intuitive conduct. For instance, utilizing occasions, the application executes custom code at whatever point the ROI changes position. As a comfort, the tool stash incorporates an equal arrangement of accommodation capacities for ROI creation [12]. A locale of intrigue (ROI) is a bit of a picture that needs to channel or play out some other procedure on. The ROI is characterized by making a paired veil, which is a parallel picture that is a similar size as the picture need to process with pixels that characterize the ROI set to 1 and every other pixel set to 0 .

The regions could be geographic, for example, polygons that include adjacent pixels, or they are characterized by a scope of forces. In the last case, the pixels are not contiguous. A neural system is a figuring model whose layered structure takes after the arranged structure of neurons in the cerebrum, with layers of associated hubs [13]. A neural system gains from information, so it tends to be prepared to perceive designs, arrange information, and estimate future occasions. A neural system separates the contribution to layers of deliberation. It is prepared over numerous guides to perceive designs in discourse or pictures, for instance, similarly as the human mind does [1415]. These loads are consequently balanced during preparing as 
indicated by a predefined learning rule until the neural system plays out the ideal assignment effectively. Neural systems are particularly appropriate to perform design acknowledgment to recognize and order items or signals in discourse, vision, and control frameworks. They are utilized for performing timearrangement expectations and demonstrating. Here are only a couple of instances of how neural systems are utilized. Power organizations precisely gauge the heap on their electric matrices to guarantee unwavering quality and upgrade the effectiveness of the force generators they work. ATMs dependably acknowledge bank stores by perusing the record number and store sum on check. Pathologists depend on disease recognition applications to control them in grouping tumors as generous or dangerous, in light of the consistency of cell size, cluster thickness, mitosis, and different elements.

Table 1: Comparative study of existing research works.

\begin{tabular}{|c|c|c|c|c|}
\hline & AUTHORS & IDEA & RESULT & DRAWBACK \\
\hline 1. & $\begin{array}{l}\text { M. Lega et } \\
\text { al. [9] }\end{array}$ & $\begin{array}{l}\text { The proportion of sun } \\
\text { situated radiation } \\
\text { reflected from land } \\
\text { and sea surfaces, } \\
\text { similarly as the } \\
\text { amount,absorbed, } \\
\text { depends not } \\
\text { completely upon that } \\
\text { portion of } \\
\text { imperativeness from } \\
\text { the sun that shows up } \\
\text { at these surfaces. A } \\
\text { warm sensor } \\
\text { distinguishes } \\
\text { splendid essentialness } \\
\text { from a surface goal, } \\
\text { warmed through } \\
\text { radiation, convection, } \\
\text { and conduction; thus, } \\
\text { it is extremely } \\
\text { difficult to get an } \\
\text { exact temperature of } \\
\text { a thing using only } \\
\text { this strategy. }\end{array}$ & $\begin{array}{l}\text { Infrared thermography as a } \\
\text { perfect gadget to help the } \\
\text { surface waters debasement } \\
\text { watching. By using infrared } \\
\text { thermography, specific } \\
\text { ethereal stages and pushed } \\
\text { methodology of data } \\
\text { examination and } \\
\text { discernment to locate a } \\
\text { couple of natural issues to } \\
\text { discover defilement point } \\
\text { sources and finding the right } \\
\text { route among sources and } \\
\text { targets. }\end{array}$ & $\begin{array}{l}\text { Vitality is the essential profile when } \\
\text { seen through a warm imaging } \\
\text { contraption. Emitted Energy is } \\
\text { generally what is required to be } \\
\text { evaluated. Transmitted Energy is the } \\
\text { imperativeness that experiences the } \\
\text { subject from a remote warm source. } \\
\text { Reflected Energy is the proportion of } \\
\text { essentialness that reflects off the } \\
\text { outside of the thing from a remote } \\
\text { warm source. For instance, the } \\
\text { proportion of sun controlled radiation } \\
\text { reflected from land and sea surfaces, } \\
\text { similarly as the total ingested, } \\
\text { depends fairly upon that piece of } \\
\text { essentialness from the sun that shows } \\
\text { up at these surfaces. A warm sensor } \\
\text { perceives splendid imperativeness } \\
\text { from a surface goal, warmed through } \\
\text { radiation, convection, and } \\
\text { conduction. Thus, it is exceptionally } \\
\text { difficult to get a careful temperature } \\
\text { of an article using only this strategy } \\
\text { in any case; it is incomprehensible, } \\
\text { with precision to distinguish the } \\
\text { qualification of temperature between } \\
\text { two o all the more things in a } \\
\text { comparable IR warm picture. }\end{array}$ \\
\hline 2. & $\begin{array}{l}\text { Amin Al- } \\
\text { Habaibeh et } \\
\text { al. [16] }\end{array}$ & $\begin{array}{l}\text { This paper tends to } \\
\text { the utilization of } \\
\text { infrared innovation to } \\
\text { recognize water } \\
\text { spillage from covered } \\
\text { channels. The } \\
\text { objective is to } \\
\text { recognize and find } \\
\text { the spillage in pipes } \\
\text { successfully with } \\
\text { minimal effort and } \\
\text { low goals innovation. } \\
\text { This paper looks at } \\
\text { between a low goals } \\
\text { camera and a high } \\
\text { goals camera } \\
\text { regarding spillage } \\
\text { and area recognition } \\
\text { with the help of }\end{array}$ & $\begin{array}{l}\text { The location of water } \\
\text { spillage in pipes is getting } \\
\text { critical to spare water and } \\
\text { vitality. This paper has } \\
\text { proposed the utilization of } \\
\text { low and high goals cameras } \\
\text { to test the identification of } \\
\text { water spillage utilizing a } \\
\text { little scope test system. It } \\
\text { has been discovered that } \\
\text { when spillage happens, a } \\
\text { particular warm profile will } \\
\text { be produced that could be } \\
\text { effectively identified by the } \\
\text { two kinds of cameras. The } \\
\text { cameras picture that breaks } \\
\text { despite of the whole itself } \\
\text { isn't being obvious } \\
\text { superficially by visual }\end{array}$ & $\begin{array}{l}\text { Early location of holes improves } \\
\text { operational effectiveness, brings } \\
\text { down operational expenses, } \\
\text { diminishes the potential for pollution, } \\
\text { broadens the life of the offices, } \\
\text { lessens potential property harm and } \\
\text { water framework risk, and decreases } \\
\text { water blackout occasions. A few } \\
\text { research ventures have been } \\
\text { introduced in the writing to recognize } \\
\text { water spillage utilizing diverse } \\
\text { spillage location methods, for } \\
\text { example, acoustic discharge, pressure } \\
\text { sensors, and infrared. Various } \\
\text { sensors are found to have various } \\
\text { abilities. As the water spillage causes } \\
\text { temperature contrasts in the zone } \\
\text { close by, infrared warm cameras } \\
\text { recognizes the hole by picturing the }\end{array}$ \\
\hline
\end{tabular}




\begin{tabular}{|c|c|c|c|c|}
\hline & & $\begin{array}{l}\text { picture preparing } \\
\text { strategies. This is to } \\
\text { evaluate the } \\
\text { capability of utilizing } \\
\text { inaccessible remote } \\
\text { identification of } \\
\text { spillage in water } \\
\text { frameworks that are } \\
\text { utilizing infrared } \\
\text { advancements that } \\
\text { could be prepared to } \\
\text { utilize rambles, } \\
\text { helium inflatables, } \\
\text { and planes. }\end{array}$ & $\begin{array}{l}\text { examination. The distinction } \\
\text { in the temperature produced } \\
\text { superficially has been } \\
\text { recognized by both, the high } \\
\text { goals warm camera (Flir } \\
\text { A310f) and the low goals } \\
\text { warm camera (IRISYS). Be } \\
\text { that as it may, the came } \\
\text { about pictures from the two } \\
\text { cameras have required extra } \\
\text { handling to affirm the } \\
\text { spillage and its area. }\end{array}$ & $\begin{array}{l}\text { spillage focuses upon the adjustment } \\
\text { in temperature superficially over the } \\
\text { pipeline. This paper tends to the } \\
\text { utilization of infrared innovation to } \\
\text { distinguished water spillage from } \\
\text { covered channels. }\end{array}$ \\
\hline 3. & $\begin{array}{l}\text { S.Sharma et } \\
\text { al. [17] }\end{array}$ & $\begin{array}{l}\text { These highlights } \\
\text { predestinate cooled } \\
\text { finders for particular } \\
\text { purposes } \\
\text { airborne frameworks, } \\
\text { where quick and } \\
\text { exact infrared } \\
\text { radiation estimation } \\
\text { is required. Present- } \\
\text { day infrared cooled } \\
\text { finder exhibits like } \\
\text { HgCdTe Epsilon } \\
\text { indicator } \\
\text { Sofradir with a } \\
\text { phantom scope of } \\
3.5 \mu m-5 \mu m \text { furnishes } \\
\text { the high edge rate } \\
\text { arriving at 140Hz } \\
\text { with full edge } \\
\text { readout. Expanding } \\
\text { outline paces of } \\
\text { cooled infrared } \\
\text { identifiers requests } \\
\text { quick and proficient } \\
\text { picture handling } \\
\text { modules for vital } \\
\text { activities like non } \\
\text { uniformity terrible } \\
\text { amendment, tom } \\
\text { pixel substitution, } \\
\text { and representation. }\end{array}$ & $\begin{array}{l}\text { The mechanical } \\
\text { arrangement relies upon } \\
\text { crude water attributes, } \\
\text { moderateness, and } \\
\text { worthiness and, level of use. } \\
\text { Supportability relies upon } \\
\text { attention to the related } \\
\text { issues. Since there are } \\
\text { confinements in each } \\
\text { treatment advancements } \\
\text { along these lines, half breed } \\
\text { advances are constantly } \\
\text { advantageous, } \\
\text { notwithstanding, } \\
\text { accessibility, } \\
\text { improvement, and so forth } \\
\text { are significant for the best } \\
\text { exhibitions of the } \\
\text { framework. Finally, it must } \\
\text { be referenced through the } \\
\text { betting of research that the } \\
\text { eventual fate of the water } \\
\text { treatment innovation is } \\
\text { profoundly prosperous 'new } \\
\text { water for everybody'. }\end{array}$ & $\begin{array}{l}\text { A few research ventures have been } \\
\text { displayed in the writing to } \\
\text { distinguish water spillage utilizing } \\
\text { distinctive spillage location systems, } \\
\text { for example, acoustic discharge, } \\
\text { pressure sensors. Infrared } \\
\text { Extraordinary sensors are found to } \\
\text { have various abilities, for instance at } \\
\text { the point when water is siphoned at a } \\
\text { generally high weight, it could be } \\
\text { hard to recognize the weight drop } \\
\text { brought about by a spillage. Thus } \\
\text { pressure sensors could neglect to } \\
\text { identify. Additionally, a few sensors } \\
\text { could be costly and would require } \\
\text { conveyed establishment around the } \\
\text { water framework. As the water } \\
\text { spillage causes temperature contrasts } \\
\text { in the region close by, infrared warm } \\
\text { cameras recognizes the break by } \\
\text { picturing the spillage focuses upon } \\
\text { the adjustment in temperature } \\
\text { superficially over the pipeline. }\end{array}$ \\
\hline 4. & $\begin{array}{l}\text { Surekha } \\
\text { Dudhani } \\
\text { al. [18] }\end{array}$ & $\begin{array}{l}\text { This paper exhibits } \\
\text { the job of } \\
\text { computerized picture } \\
\text { preparing (DIP) for } \\
\text { space explicit ID and } \\
\text { evaluation of water } \\
\text { assets created in the } \\
\text { Visual Basic (VB) } \\
\text { stage from a satellite } \\
\text { picture. }\end{array}$ & $\begin{array}{l}\text { The technique introduced in } \\
\text { the paper shows an orderly } \\
\text { and exhaustive } \\
\text { computational way to deal } \\
\text { with extricating data for } \\
\text { distinguishing proof and } \\
\text { evaluation of water assets } \\
\text { for differentiated fields of } \\
\text { utilizations. }\end{array}$ & $\begin{array}{l}\text { Manual overviews and refreshing of } \\
\text { the data isn't just tedious yet } \\
\text { additionally requires enormous labor } \\
\text { because of the undulating geology, } \\
\text { thick woods spread, and terrible } \\
\text { climatic conditions. Albeit direct cost } \\
\text { examinations of water asset the board } \\
\text { by utilizing satellite pictures and } \\
\text { regular strategies are not accessible } \\
\text { for comparable work, it is normal } \\
\text { that proposed philosophy might be a } \\
\text { suitable answer for visit refreshing of } \\
\text { the data. }\end{array}$ \\
\hline
\end{tabular}




\section{CONCLUSION}

In the future, the proposed system helps the rural people by detecting the water quality of wells using client-server technology and thereby preventing waterborne diseases that are not much concentrated in rural areas so far. The system detects the contaminants to find its way into water packets and bottles without taking much time and at low-cost image processing technology extracts information from pictures and coordinates it for a wide scope of utilizations. Here, the delineated most unmistakable fields where picture preparation could bring critical advantages.

\section{ACKNOWLEDGMENT}

The authors wish to thank the Karunya management for all the supports.

\section{REFERENCES}

[1]. Ahlberg and A. Berg, "Evaluating template rescaling in short-term single-object tracking", In Advanced Video and Signal Based Surveillance, pp. 1-4, 2015.

[2]. Bay A, Ess T, Tuytelaars, and L. Van Gool, “'Speeded-up robust features (SURF)",Computer Vision and Image Understanding, vol.110, no. (3), pp. 346-359, 2008.

[3]. Berg J. Ahlberg and M. Felsberg, "A thermal infrared dataset for evaluation of short-term tracking methods". In Swedish Symposium on Image Analysis (SSBA), 2015.

[4]. Berg, M. Felsberg, G. Häger, and J. Ahlberg, "An overview of the thermal infrared visual object tracking VOT-TIR2015 challenge", In Swedish Symposium on Image Analysis, 2016.

[5]. Briechle and U.D. Hanebeck, "Template matching using fast normalized cross correlation", Optical Pattern Recognition, vol. 4387, pp. 95-102, 2001.

[6]. W. Davis and V. Sharma, "Background-subtraction using contour-based fusion of thermal and visible imagery", Computer Vision and Image Understanding, vol. 106, pp.162-182, 2007.

[7]. T. Zin, R. Takahashi, and H. Hama, "Robust person detection using far infrared camera for image fusion", In Innovative Computing, Information and Control, 2007, pp. 310-310, 2007.

[8]. Zhang $\mathrm{B}, \mathrm{Wu}$, and $\mathrm{R}$. Nevatia, "Pedestrian detection in infrared images based on local shape features", In Computer Vision and Pattern Recognition (CVPR),pp. 18, 2007.

[9]. Lega M, Napoli R.M.A, Persechino G, and Schiano P, "EMPA Project: Conquering the Third Dimension in Ambient Air Monitoring", U.S. EPA's 2009 National Air Quality Conference, 2009.

[10]. Short N.M, "The warm Earth - Thermal Remote sensing", 2009.

[11]. Lega $M$ and Napoli R.M.A., "New guidelines for Environmental Monitoring and advanced technologies for 3D field data acquisition", Convegno Nazionale di Fisica della Terra Fluida e Problematiche Affini, Ischia, pp. 11-15, 2007.
[12]. Stockton G.R, "Finding pollution with aerial infrared thermography", The Industrial Physicist Magazine, 2004.

[13]. Stockton G.R, "Application and Methodology for Locating storm-water discharges using aerial infrared thermography", Inframation, 2003.

[14]. Hun-wei, Lee J and Choi D.K.W, Arega F, "Environmental Management of Mariculture", 2002.

[15]. Maldague X.P.V, Jones T.S, Kaplan H, Marinetti S, and Prystay M, "Chapter 2: Fundamentals of Infrared and Thermal Testing: Part 1. Principles of Infrared and Thermal Testing, "Nondestructive Handbook, Infrared and Thermal Testing, X. Maldague technical ed., P. O. Moore ed., 3rd edition, Columbus, Ohio, ASNT Press, vol.3, 2001.

[16]. A. Al-Habaibeh, Bubaker Shakmak, and Simon Fanshawe, "The development of an experimental test rig to evaluate the performance of a new technology for stratified hot water storage -The Water Snake", Energy Procedia, vol.142, pp. 3644-3653, 2017.

[17]. S. Sharma and A. Bhattacharya, "Drinking water contamination and treatment techniques" ,Applied Water Science, vol. 7, pp.1043-1067, 2017.

[18]. Surekha Dudhani, Ashok Sinha, and S. S. Inamdar,"Role of Digital Image Processing for Interfacing of Remote Sensing data for Water resource analysis and planning", Map India, 2020. 